\title{
With Individualized Abutments to Achieve More Success in Implant Therapy
}

\author{
Ali-Reza Ketabi ${ }^{1^{*}}$, Sandra Ketabi ${ }^{1}$ and Bernd Helmstädter ${ }^{2}$ \\ ${ }^{1}$ Medical Dentistry, Private Practice, Epplestr. 29a, Stuttgart, Germany \\ ${ }^{2}$ Master Dental Technician Filder Dental LaboratoryNeuer Markt 5, 70771 Leinfelden, Germany
}

*Corresponding author: Dr. Ali-Reza Ketabi, Doctor of Medical Dentistry, Private Practice, Epplestrasse 29A, Stuttgart, Germany, Tel: +49 $711-4400952 ;$ Fax: +49 711 - 633969 78; E-mail: alirezaketabi@yahoo.de

Received date: September 05, 2017; Accepted date: September 08, 2017; Published date: September 15, 2017

Copyright: @ 2017 Ketabi AR, et al. This is an open-access article distributed under the terms of the Creative Commons Attribution License, which permits unrestricted use, distribution, and reproduction in any medium, provided the original author and source are credited.

\section{Introduction}

The use of osseointegrated, dental implants as a complement and extension of the conventional dental treatment spectrum is becoming increasingly important. Several factors are responsible for the success of implant prosthetic treatment: in addition to modern implant surfaces, stable implant-abutment connections [1] as well as optimal peri-implant hard and soft tissue [2], an individual design of the emergence profile is necessary. The design of the transition from the round implant to the tooth-root-like individual profile is achieved usually by the abutment, which must be individually customized as required [3].

Prefabricated abutments have a rotationally symmetrical basic shape and do not correspond to the shape of the natural teeth in the passage area.

Various techniques for producing individual abutments have been described in the literature. The processing of prefabricated abutments from zirconium dioxide or titanium is often problematic because of the considerable reduction in the substance. Overheating of the ceramic leads to jumps in the material, postprocessing is often very time and cost intensive.

With the Atlantis VAD ${ }^{\mathrm{ma}}$ (Virtual Abutment Design, DENTSPLY IH $\mathrm{GmbH}$ ) software, abutments can be individually designed from the ideal shape of the crown. This results in a natural - aesthetic treatment $[4,5]$.

\section{The Procedure}

After Clinical and radiological examinations, an Astra Tech Osseospeed Implant (DENTSPLY IH GmbH) was inserted. After a healing period of 2 months a transfer impression was made using an impression coping (Figure 1).

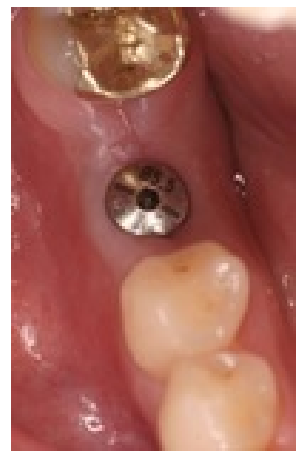

Figure 1: Clinical state2 month after implant placement (occlusal view).

A plaster casted model was produced as usual. Then the emergence profile of the future abutment was defined in the gingival mask made of silicon (Picodent Dental-Produktions Vertriebs GmbH) (Figure 2) and an as accurate as possible Wax-Up was prepared (Figure 3).

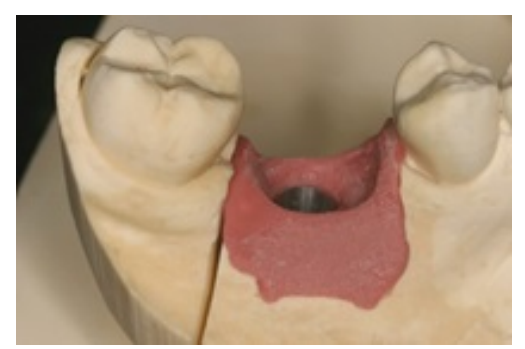

Figure 2: Die master with individual emergence profile defined in the gingival mask (buccal view). 
Citation: Ali-Reza Ketabi, Sandra Ketabi, Bernd Helmstädter (2017) With Individualized Abutments to Achieve More Success in Implant Therapy.

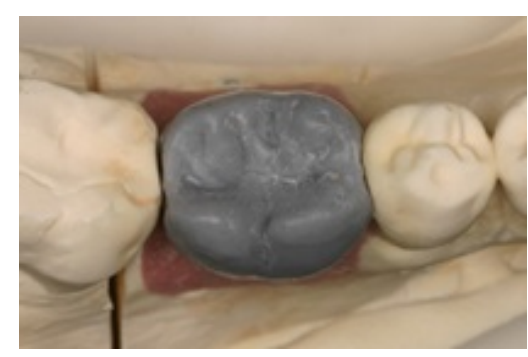

Figure 3: Die master with Wax-Up (occlusal view).

Now, virtual models of the master model and the Wax-up are manufactured with optical 3D-Scanner. The resulting data set corresponds virtually to the patient's mouth situation.

The technician himself determined the required abutment design, by transcribing the instructions firstly in a special virtual entry form, and sending the data subsequently via internet to the manufacturer. On the basis of these data, an abutment with a patient-specific emergence profile, starting from the ideal shaping of the crown, were developed. The Abutment was fabricated using the Atlantis Virtual Abutment Design-Software.

After the milling process, the finished abutment, made from a solid blank consisting of a titanium alloy of medical grade, was delivered to the technician with a corresponding abutment screw (Figure 4).

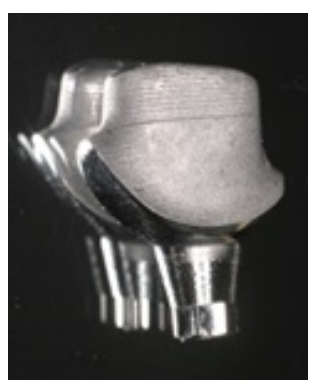

Figure 4: Titanium Atlantis abutment with individual emergence profile.

The abutment was placed on the model (Figure 5), now the superstructure can be produced in the usual way by the dental technician (Figure 6).

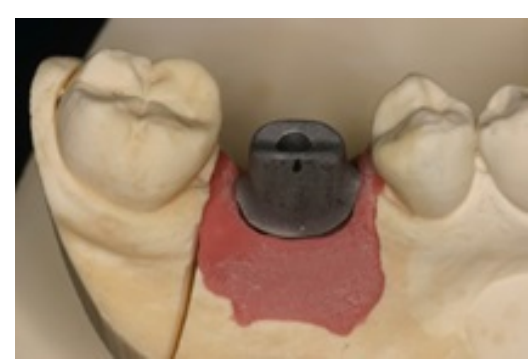

Figure 5: Die master with individual abutment (buccal view).

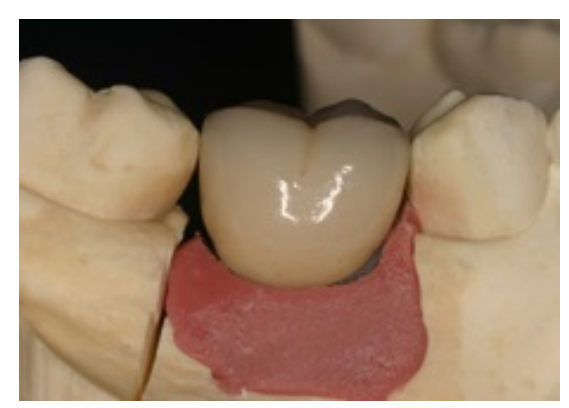

Figure 6: Die master with crown (buccal view).

The patient was provided with cemented crown, made of veneered zirconia Ceramill ZI (Amann Girrbach GmbH) (Figures 7-9).

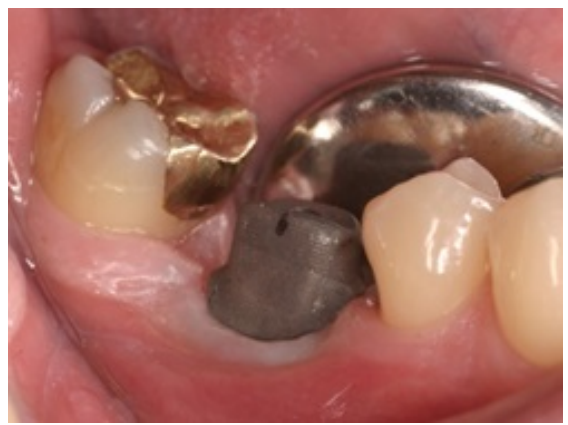

Figure 7: Clinical stateafter placement of abutments (buccal view).

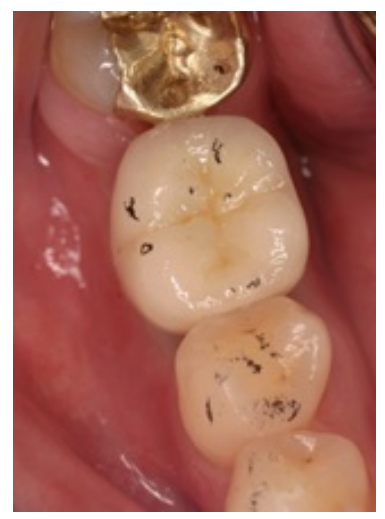

Figure 8: Clinical stateafter placement of crown (occlusal view). 
Citation: Ali-Reza Ketabi, Sandra Ketabi, Bernd Helmstädter (2017) With Individualized Abutments to Achieve More Success in Implant Therapy.

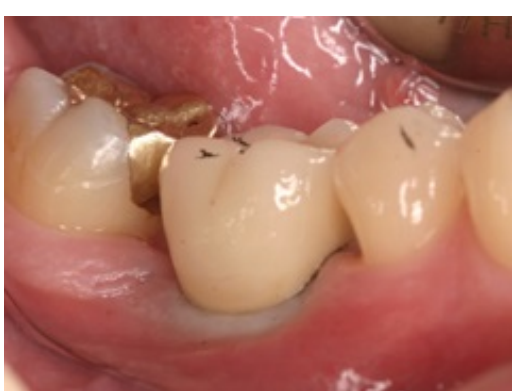

Figure 9: Clinical stateafter placement of crown (buccal view).

Clinical follow-up was performed after 4 weeks, 6 months and thereafter annually. After 20 month neither technical complications such as fractures of the veneering material or abutment fracture or loosening of the abutment nor soft tissue-complication could be observed. The peri-implant soft tissue has optimally adapted to the crown and an increase of the papilla could be observed (Figures 10 and 11).

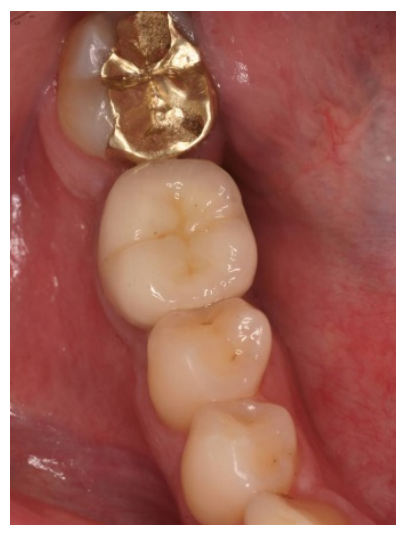

Figure 10: Clinical control examination after 20 month (occlusal view).

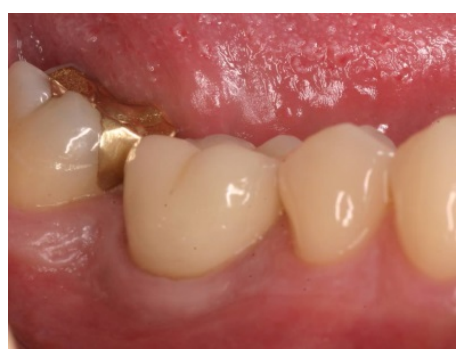

Figure 11: Clinical control examination after 20 month (buccal view).

No bone changes, on the mesial and distal aspect of the implants could be found during the observation period (Figures 12 and 13).

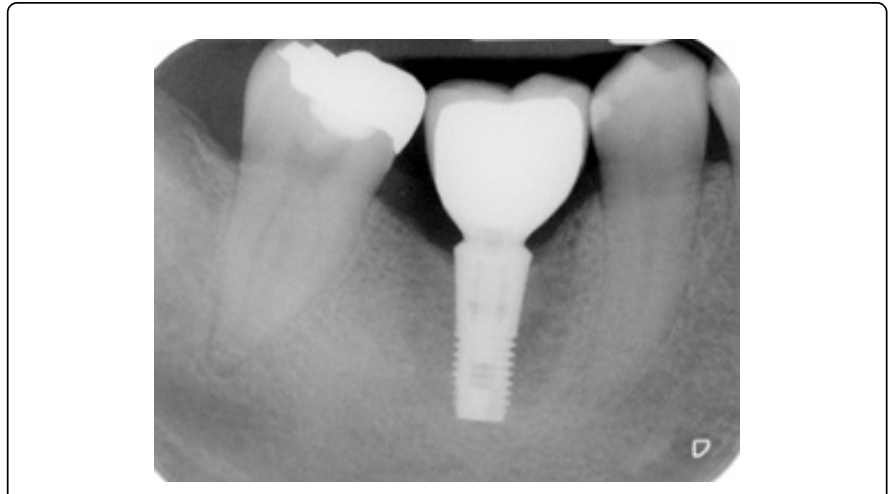

Figure 12: X-ray control after placement of abutments and crown.

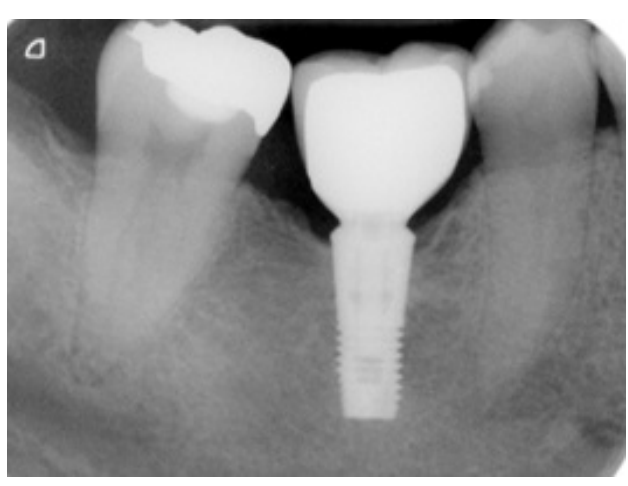

Figure 13: X-ray control after 20 month.

The results of our own clinical studies and other authors show that CAD / CAM-made abutments can simplify and accelerate the prosthetic work processes without sacrificing esthetics and function [6-8]. The method allows the production of individual abutments, starting from the ideal shape of the crown. Thus, the emergence profile can be optimized by the abutment. The marginal course can be adapted to the course of the gingiva and thus remain clinically controllable, as a result of which cement residues can be removed very simply.

Atlantis abutments offer some advantages over the previous methods for the manufacture of individual implant abutments, the application of this method can therefore be recommended.

\section{References}

1. Romanos GE (2015) Tissue preservation strategies for fostering long-term soft and hard tissue stability. Int J Periodontics Restorative Dent 35: 363-371.

2. Zhao X, Qiao SC, Shi JY, Uemura N, Arai K, Lai HC (2016) Evaluation of the clinical and aesthetic outcomes of Straumann $((\mathrm{R}))$ Standard Plus implants supported single crowns placed in non-augmented healed sites in the anterior maxilla: a 5-8 years retrospective study. Clin oral implants Res 27: 106-112.

3. Ganz SD (2003) Computer-milled patient-specific abutments: incredibly quality with unprecedented simplicity. Implantology 2003: 37-44.

4. Priest G (2005) Virtual-designed and computer-milled implant abutments. J Oral Maxillofac Surg 63: 22-32. 
Citation: Ali-Reza Ketabi, Sandra Ketabi, Bernd Helmstädter (2017) With Individualized Abutments to Achieve More Success in Implant Therapy. Dentistry 7: i102. doi:10.4172/2161-1122.1000i102

Page 4 of 4

5. Ganz SD (2003) Computer-milled patient-specific abutments: incredibly quality with unprecedented simplicity. Implantology 2003: 37-44.

6. A. Ketabi, G. Bornemann, H.-Chr. Lauer (2011) Retrospektive Nachuntersuchung von CAD/CAM gefertigten Implantatabutments. Int Poster J Dent Oral Med 13: 543.
7. Ketabi AR, Ketabi S, Brenner M, Lauer HC, Brandt S (2017) Retrospective Analysis of Biological and Technical Complications Using Individual CAD/CAM Abutments. Dentistry 7: 449

8. Garg AK (2002) The Atlantis Components Abutment: simplifying the tooth implant procedure. Dent implantol update 13: 65-70. 